\title{
Trend analysis of library book circulation of the Open University of Sri Lanka
}

\author{
M.M.I.K. Marasinghe ${ }^{1}$
}

\begin{abstract}
This study examined the book circulation pattern of the main library of the Open University of Sri Lanka with the aim of identifying the pattern of circulation of printed books. Moreover, this study analyzes the subject wise variation of users' demand during the 05 years and explores the internal factors affecting the process of book borrowing. The study covers the 05 years from 2014-2018 periods for the analysis. This study applied the quantitative research approach and the secondary data taken from the "Koha" Library Management system for the period of 2014 to 2018 was taken for the study. Data presented through descriptive statistics such as percentages, frequency, and correlation analysis with graphical representations. The results of the study indicated that the total annual book borrowings have been declined over the years in parallel to the falling rate of annual book borrowers. Literature, technology and social sciences were the subject areas with the highest demand and religion, history $\&$ geography, and arts were the least in- demand categories over the last 05 years from 2014 to 2018. It could be identified that education was the only subcategory with an increasing rate of book borrowing. It is important to carry out a study to explore possible causes for the decline in book borrowings and changes that took place in the information-seeking behavior of the library users.
\end{abstract}

Keywords: Book borrowing, Circulation pattern, User demand, Sri Lanka

\footnotetext{
${ }^{1}$ Assistant Librarian, Open University of Sri Lanka. Email: mmmar@ou.ac.lk

(iD) https://orcid.org/0000-0003-3487-5916
} 


\section{Introduction}

Systematic evaluation of existing collection is important to take economically effective decisions in the collection development; as the library budget and existing physical space are some main limiting factors in expanding library resources and services.

Circulation analysis is one approach that can be used to conduct user studies and collection evaluation in the libraries; as it gives an indication of the relevancy of the collection to the user population. The results of the circulation analysis can be applied for may purposes including; evaluating collection acquisition policies, guiding management decisions such as acquisition, discarding, preservation, remote storage and allocating physical space for materials (Knievel, Wicht and Connaway, 2006).

This study was analyzed the trend of book circulation in the main library of the Open University of Sri Lanka, facilitating the evaluation of the changes took place, specially in the user demands for the printed books over the years. It provides an accurate overview in determining the future information requirements of the library users and to prioritize the subject streams in the collection development to achieve an active collection. Further, this study provides an indication about how reading behavior of the Open University community has changed in the digital era along with the vast availability of online information resources.

The Open University of Sri Lanka is the foremost institute which is established to provide open and distance learning within the Sri Lankan university system. It facilitates students to achieve higher educational qualifications which require for greater achievements during their career. Open and distance learning is the teaching mode used by the Open University of Sri Lanka which is totally different from the teaching mode of the conventional university system. Distance education requires more students and academic management and more learner support. Hence, the Open University provides learner support through different means including providing course materials, increasing use of online learning techniques and tools, increasing access to online resources and expanding Library services and facilities, etc. 
Library is an integral part of the Open University offering academic support for distance learners. It mainly provides the information required by the students during their learning in the forms of both printed and online. Library has been moving towards prosperity through enriching the printed book collection, increasing the online resources and services and providing user education services in order to cater the information requirements of the distance learners.

Circulation service and library online resources are the two major information accession methods available through the library for distance learners to engage in learning from their own places. Circulation service is one of the major services provided through the library and lending collection of the library has been expanding over the time to meet the requirements of the library users including both students and the university staff. Availability of electronic devices in the library, as well as the number of electronic resources has been increasing with time to facilitate the online information retrieval, especially to serve for the distance learners.

In economic theory, the law of supply and demand is considered as one of the fundamental principles governing in an economy. This concept is applicable to any subject discipline including Library Science. There should be a considerable demand for the product or the service supplied by a particular party in order to be effective. As well as, entity should identify the highest demanded goods and services to allocate the existing resources efficiently and effectively. Library as a service providing industry, there should be a good demand for the resources and services offered through the library and library must pay attention to the highest demanded resources, specially the subject areas of highest demand, in order to develop an effective book collection. Accordingly, this study was centered on the problem of how library user demand varied among different subject categories over the years. Book circulation statistics is a possible measure which can be used to evaluate the library user demand changes. Therefore, this study focuses on the analysis of book circulation pattern over the 05 years from 2014 to 2018 . 
The results of the study would be beneficial for the governing body of the University in making decisions on expanding the library resources specially printed resources as well as to identify the subject streams which needs priority during budgetary allocations.

\section{Research Objectives}

The overall objective of the study was to analyze the trend in circulation of printed resources in various subjects over the 05 years from 2014 to 2018. Specific objectives were;

i. To study the pattern of circulation of printed books over the 05 years from 2014 to 2018

ii. To analyze the subject wise variation of user demand to identify subjects with highest demand and least demand during the period of 2014 to 2018

iii. To explore internal factors affecting the rate of book borrowing

\section{Literature Review}

Development of an effective library collection is an important factor which determines the quality of the library. The main objective of any library is to provide right information for the right person at the right time. This can be achieved through evaluating the library user demand as it provides a quantitative feedback from users which can be used for improving future collection development. Circulation data is an easily accessible and valid source which can be used to identify the user demand variations among different subject categories of the book collection.

Day and Revill (1995) stated that "circulation is the strongest single element we have on which to base decisions and we feel that the analysis of this data provides a useful tool; a tool that could be used by our subject librarians along with their professional judgment and user satisfaction surveys to evaluate and fine-tune their collections"

Several past studies have used the circulation data as an attempt to improve collection development and to take decisions on to what should be given the highest priority and least priority. Carpenter and Getz (1995) examined which subjects in the Vanderbilt economics collection had the highest 
percentage of books published during a specific year that had failed to circulate at all.

Ochola (2002) examined the average circulation and the ratio of interlibrary loan borrowings to holdings in Baylor libraries to decide how to re-allocate collection resources. Knievel, Wicht, and Connaway (2006) used interlibrary loan data, average circulation, and percentage of items that circulated during a specific time period in order to inform collection development on a subject level. They further suggested that a same study could be carried out to examine books by publisher or language as well as by subjects.

A study conducted by Adams and Noel in 2008 on circulation statistics in the evaluation of collection development found that mathematics books were the most demanded and the astronomy collection lagged behind all other subjects in relation to the percentage of items used and the average number of checkouts.

A study on circulation statistics and interlibrary loan data in collection management conducted at the University of Colorado, identified, anthropology, Psychology and sociology were extremely popular subjects in the university and chemistry had a generally low circulation, which is partially due to extreme dominance of serials in library expenditures toward chemistry (Knievel, Wicht, \& Connaway, 2006).

Several studies conducted on the trend of the circulation statistics pointed out to an undeniable downward trend in use of some academic or research library print collections over the years.

Creaser et al., (2006) found that set of UK public libraries borrowing levels show distinct downward trends. Annual statistics of the Association of Research Libraries in United States showed that, starting in 1996, circulation transactions started to decline, and in 2000 dropped below 1991 levels for the first time (Kyrillidou, 2006).

A survey conducted by the Bradshaw \& Nichols, 2004 in the USA also found a decline in reading and further stated that there is a loss of around 20 
million readers who will no longer borrow from libraries nor purchase print materials from book shops.

Banks (2002) stated that there was a steady downward trend of overall circulation per week during each of the last five years and she further found that 43 percent of the random sample titles have never circulated and 18 percent circulated once.

A contradictory finding was emerged from a study conducted by Cheung and Chung in 2011 about the monograph circulation over 15 years in the liberal arts university which concluded that the book checkouts rise each year during the first five to seven years of a book's arrival and stabilize after that period.

These literatures ascertained the importance of circulation data as a means of evaluation of collection and identification of reading behavior and user demand variations.

\section{Methodology}

Quantitative research approach was followed and secondary data in relation to the book circulation taken from the Library Management System "Koha" was used in the study. The study was conducted in the Main library, The Open University of Sri Lanka that provides resources and services required by the staff and students for their teaching, learning and research purposes.

Annual book circulation data were extracted from the Library Management System of the Open University of Sri Lanka for the period of 2014 to 2018 and analyzed across subject areas.

According to the literature, book circulation data is one of the most accurate measures that can be used to examine the changes occurred with time in using of printed information resources and it also can be used to analyze the subject wise variation of book circulation to derive most demanded and least demanded books. 
Carrigan (1996); Hamaker (1995); Knievel, Wicht and Connaway (2006) all discussed the evaluation of circulation and ILL data by subject area. As Carrigan in 1996 stated, "Circulation data must be analyzed at the macro level (across subject areas, not title by title) to bear significance on resource allocation and guide collection development".

Accordingly, analysis of the book circulation pattern from 2014 to 2018 was focused on the following aspects.

1. Annual book borrowings

2. Annual book borrowers

3. Subject-wise variation of annual book borrowings using the Dewey decimal classification (DDC $)$ scheme $\left(01^{\text {st }}\right.$ divisions)

4. Further analysis of Subject-wise variation of annual book borrowings using DDC scheme $\left(02^{\text {nd }}\right.$ divisions)

Following table shows the 10 main classes of the $01^{\text {st }}$ division of the Dewey decimal classification (DDC) scheme.

Table 01: 10 main classes of the DDC

\begin{tabular}{ll}
\hline Number & Class/ Subject \\
\hline 000 & Computer science, information \& general works \\
100 & Philosophy \& psychology \\
200 & Religion \\
300 & Social sciences \\
400 & Language \\
500 & Science \\
600 & Technology \\
700 & Arts \& recreation \\
800 & Literature \\
900 & History \& geography \\
\hline Source: DDC $23^{\text {rd }}$ edition, 2011
\end{tabular}

Tabulation analysis, graphical representations were basically used to present the data and basic descriptive statistics such as percentages, frequency, and 
correlation analysis were used for the data analysis. Data were analyzed using Statistical Package for Social Sciences (SPSS) 20 version.

The annual growth rate of book borrowings was used as a measure of identifying the relative changes took place over the years.

$$
\text { Annual Growth Rate } \%=\frac{\text { (Present year value }- \text { Previous year value })}{\text { Previous year value }} \times 100
$$

\section{Results and Discussion}

\section{Total Number of Annual Book Borrowings}

Figure 01 presents the total annual book borrowings from 2014 to 2018 with the annual growth rate percentages. Accordingly, it shows a decreasing trend over the years and a huge decrease shown in the year 2018 as it has decreased by $25.9 \%$, from 16,676 book borrowings in 2017 to 12,362 book borrowings in 2018. The year 2016 also showed a huge decrease in annual book borrowings from 23,592 in 2015 to 17,806 in 2016 . The annual growth rate percentage of book borrowings in 2016 is $-24.53 \%$.

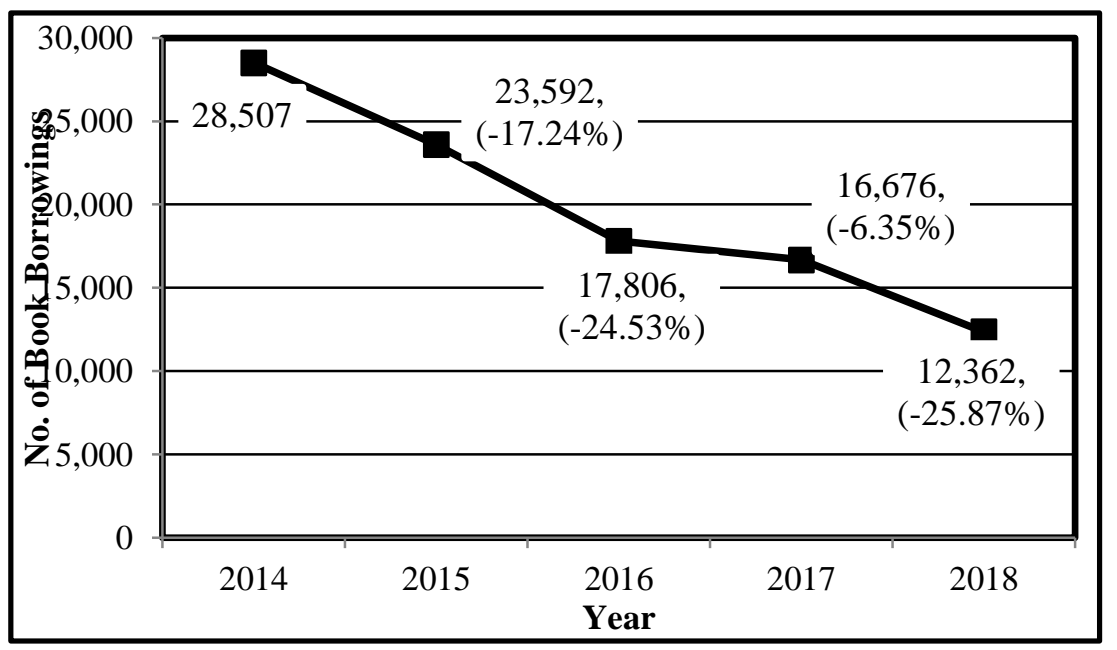

Figure 01. Annual book borrowings for the period of 2014 to 2018

However, correlation analysis was conducted to figure out the association between annual book borrowings and the number of library closing days to 
find out the effect of holidays on the rate of book borrowings. The results indicated that there is no correlation between books borrowings and the number of library closing days even at the 0.1 significance level.

Table 02. Correlation between annual book borrowings and library closing days

\begin{tabular}{llc}
\hline & & Library closing days \\
\hline Annual book & Pearson Correlation & -.701 \\
borrowings & Sig. (2-tailed) & $\mathbf{. 1 8 7}$ \\
& Number of valid observations & 5 \\
\hline
\end{tabular}

Source: Survey data

There are two ways in which annual book borrowings could have decreased, either there are fewer people borrowing books, or there is the same number of borrowers but they take out fewer books over the years.

Figure 02 illustrates number of book borrowers over the years and the annual growth rate percentages. Accordingly, number of book borrowers has decreased from 2014 to 2018 with a huge decrease shown in 2018 in which total number of book borrowers was 1,583 and it is a $20.77 \%$ decrease than the year 2017.

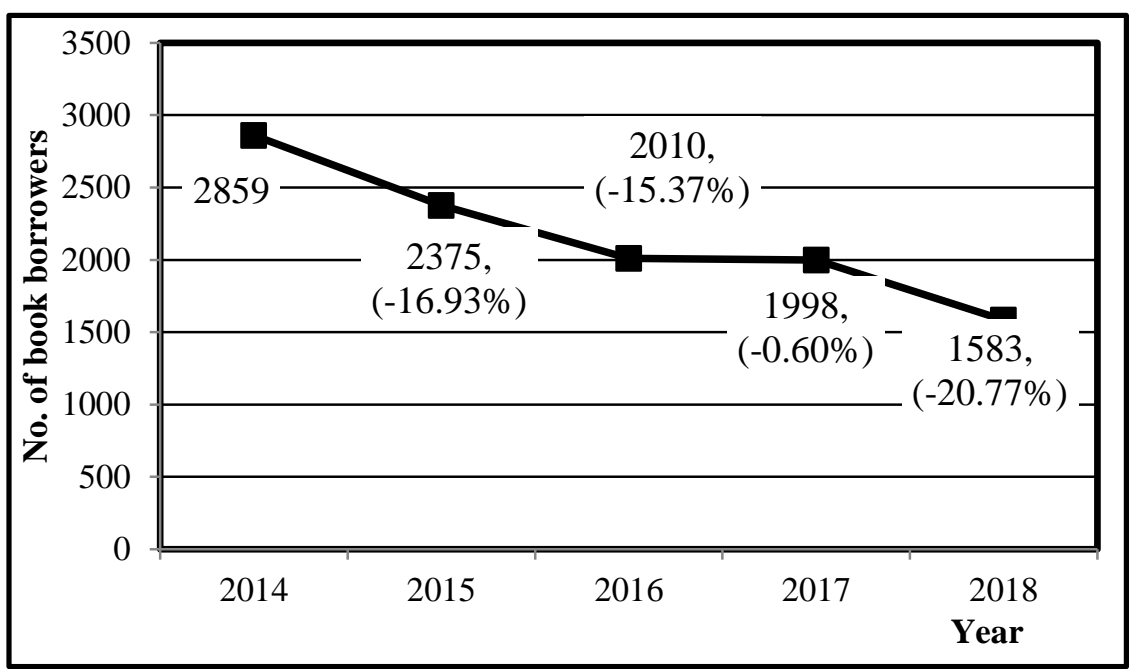

Figure 02. Number of book borrowers from 2014 to2 018 
However, the changing pattern of the number of book borrowers from 2014 to 2018 is fairly similar to the changing pattern of number of book borrowings over the years. Therefore, Correlation analysis was carried out to derive a statistical relationship between annual book borrowings and number of book borrowers (Table 03). The results indicated that there is a strong positive relationship between annual book borrowings and the number of book borrowers. This suggests that the reduction of annual book borrowings is affected by the decreased number of book borrowers.

Table 03. Correlation between annual book borrowings and number of borrowers

\begin{tabular}{llc}
\hline & & Number of borrowers \\
\hline Annual book & Pearson Correlation & $0.989 * *$ \\
borrowings & Sig. (2-tailed) & $\mathbf{0 . 0 0 1}$ \\
& Number of valid observations & 5 \\
\hline \multicolumn{2}{l}{ Source: Survey data, $* *$. Correlation is significant at the 0.01 level (2-tailed). }
\end{tabular}

Source: Survey data, ${ }^{* *}$. Correlation is significant at the 0.01 level (2-tailed).

Subject-wise variation of books borrowing

The main objective of this study was to investigate the circulation trend of printed resources over the years among various subjects. All book transactions for the last 05 years from 2014 to 2018 were used for the analysis and categorized into ten main subjects using the 01st divisions of DDC scheme. Table 04 shows the subject-wise and year-wise distribution of borrowed books and percentage of borrowed books under each subjects.

Table 04. Subject-wise variation of books borrowing

\begin{tabular}{lccccccc}
\hline Subject & \multicolumn{9}{l}{ Number of borrowed books by year } & & Total \\
\cline { 2 - 6 } & $\mathbf{2 0 1 4}$ & $\mathbf{2 0 1 5}$ & $\mathbf{2 0 1 6}$ & $\mathbf{2 0 1 7}$ & $\mathbf{2 0 1 8}$ & $\begin{array}{l}\text { Percentage } \\
\text { by total } \\
(\boldsymbol{\%})\end{array}$ \\
\hline Literature & 7,097 & 5,422 & 4,168 & 3,859 & 3,443 & 23,989 & 24.26 \\
Technology & 7,092 & 5,409 & 3,981 & 3,784 & 2,511 & 22,777 & 23.04 \\
Social sciences & 5,268 & 5,096 & 3,463 & 3,763 & 2,757 & 20,347 & 20.58 \\
Science & 3,656 & 3,026 & 2,470 & 2,115 & 1,496 & 12,763 & 12.91 \\
Computer science, & 2,285 & 1,980 & 1,672 & 1,209 & 892 & 8,038 & 8.13 \\
information \& & & & & & & & \\
\hline
\end{tabular}




\begin{tabular}{|c|c|c|c|c|c|c|c|}
\hline \multicolumn{8}{|l|}{ general works } \\
\hline Language & 941 & 750 & 697 & 498 & 460 & 3,346 & 3.38 \\
\hline $\begin{array}{l}\text { Philosophy \& } \\
\text { psychology }\end{array}$ & 742 & 724 & 520 & 535 & 264 & 2,785 & 2.82 \\
\hline Religion & 714 & 565 & 418 & 400 & 250 & 2,347 & 2.37 \\
\hline $\begin{array}{l}\text { History \& } \\
\text { geography }\end{array}$ & 528 & 457 & 305 & 385 & 251 & 1,926 & 1.95 \\
\hline Arts \& recreation & 135 & 157 & 107 & 121 & 36 & 556 & 0.56 \\
\hline
\end{tabular}

Source: Survey data

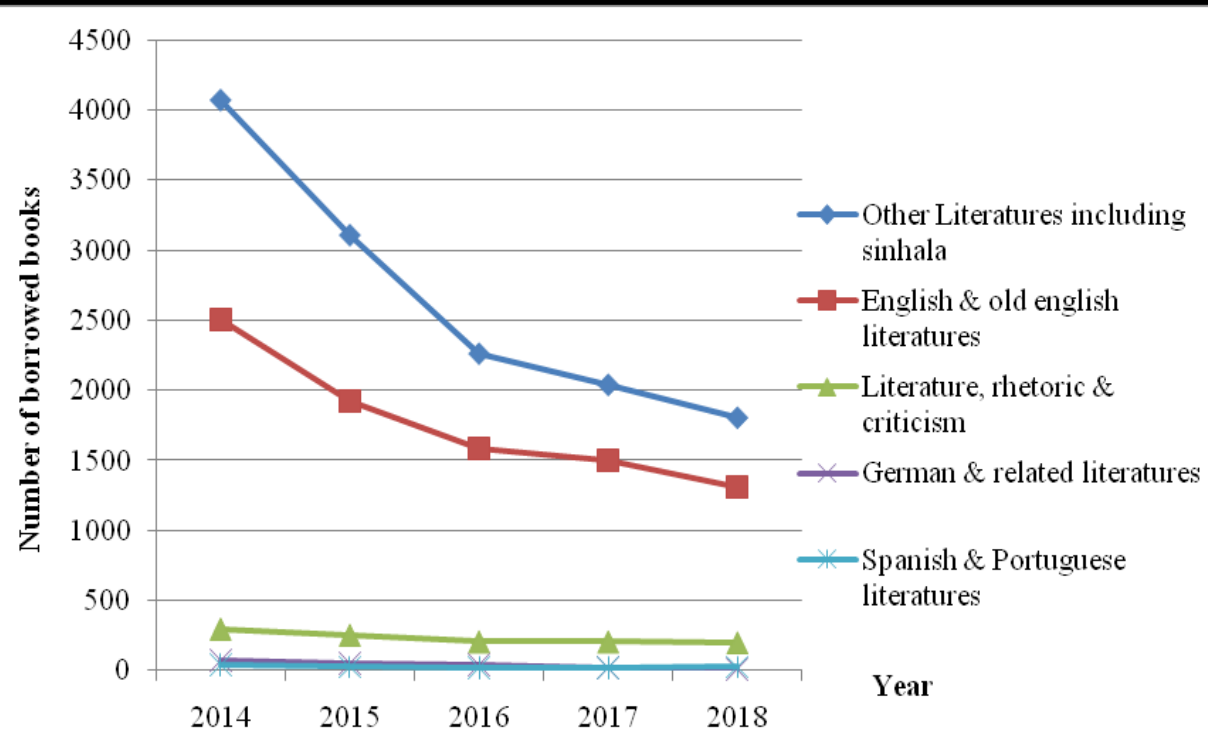

Figure 03. Top five subcategories under the literature (DDC class 800) for the period of 2014 to 2018

Accordingly, it could be identified that the most demanding and least demanding subjects over the last 05 years in relation to the books circulations. Literature (24\%) was the subject with the highest demand over the 05 years from 2014 to 2018, followed by technology (23\%) and social sciences $(20 \%)$. Therefore, literature, technology and social sciences were the subject areas with the highest demand over the last 05 years.

Subjects with the least demand were religion, history and geography, and arts and the borrowing rates were $2 \%, 2 \%$ and $0.6 \%$ respectively. 
Most demanding subject categories; literature, technology and social sciences were further analyzed to find out top 05 subcategories in each main class. Second divisions of DDC scheme was used for this purpose.

Figure 03 illustrates the variation of number of book borrowings belongs to the literature category. Sinhala literature found to be the subcategory with highest, followed by English and old English literatures. This indicated that the books on Sinhalese fiction, drama, poetry, literature Etc. are the most demanding books of the library. German literature and the Spanish and Portuguese were the subcategories with least demand and showing a similar pattern of variation over the years from 2014 to 2018. However, the results showed a decreasing trend over the years in all five subcategories.

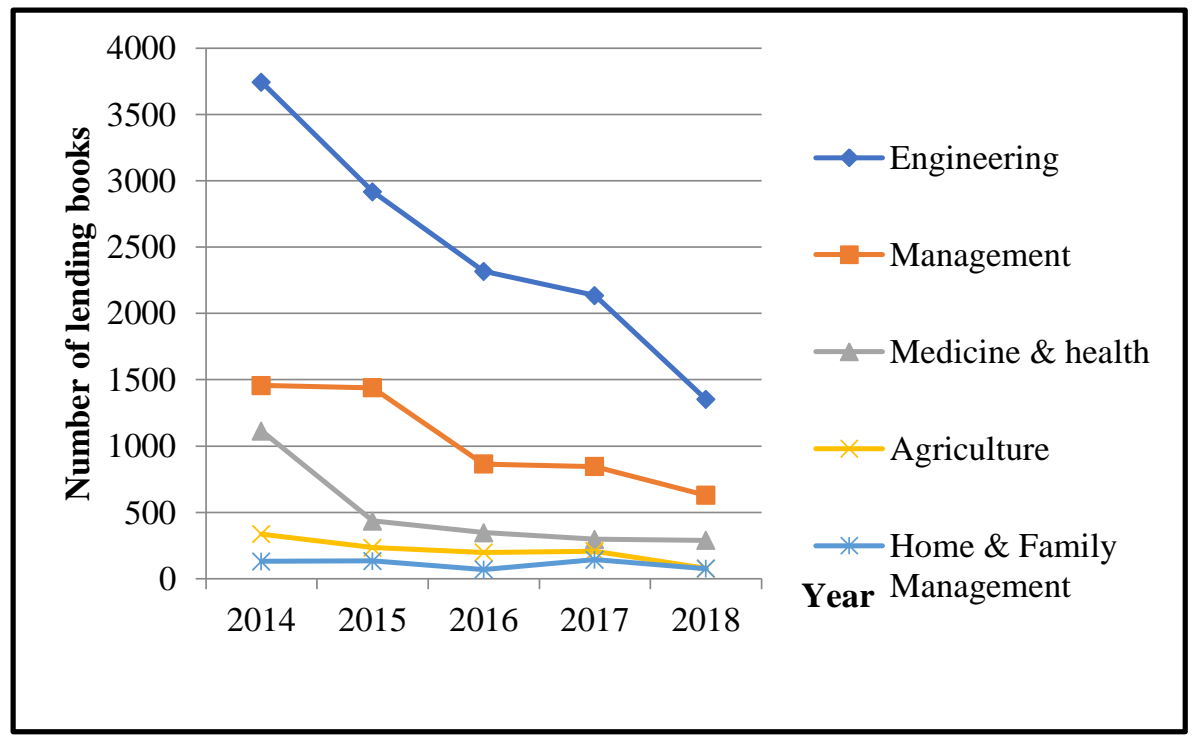

Figure 04. Top five subcategories under the main class of technology (DDC class 600) 2014-2018

Next subject category with highest demand was technology in which engineering, management, medicine \& health, agriculture and home \& family management were the subcategories with a higher demand (Figure 04). This categorization was taken from the 02nd summary of the DDC scheme. Accordingly, engineering and management were the most popular subcategories among the book borrowers. However, all five subcategories showed a decreasing trend over the 05 years from 2014 to 2018. 


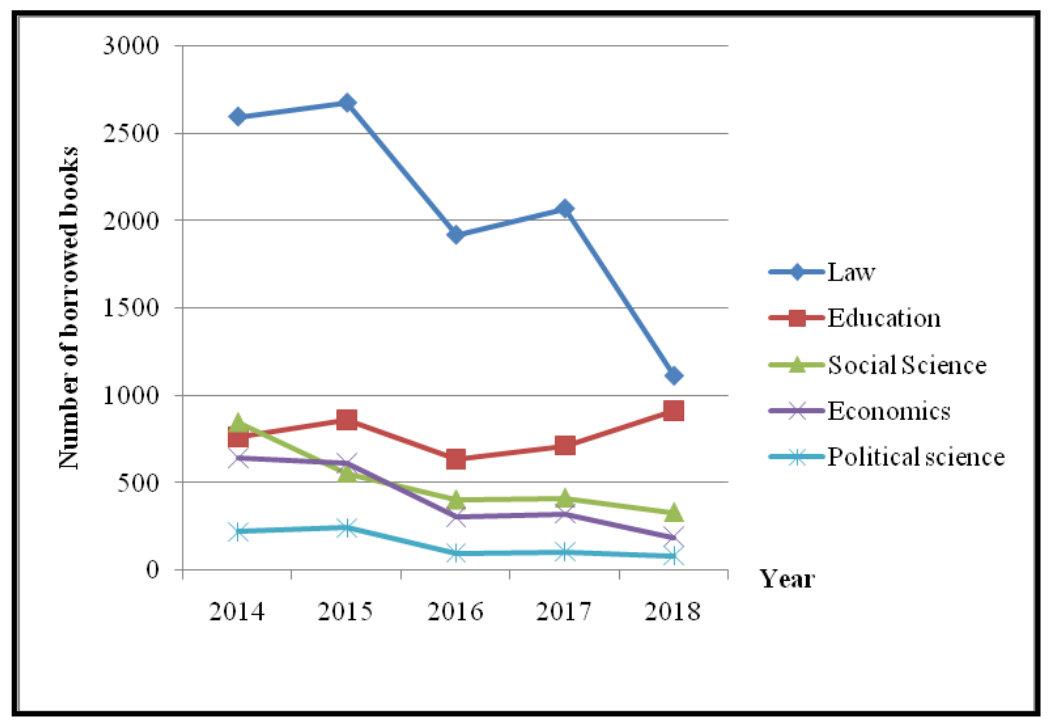

Figure 05. Top five subcategories of social science (DDC class 300) from 2014 to 2018

Top 05 Subcategories of social sciences showed a different pattern than the literature and technology subjects. According to figure 05, law was the most demanding subcategory and the borrowing pattern has varied considerably over the years. Education books borrowing pattern showed an increasing trend over the years. Subcategories of social science, economics, and political science showed a decreasing trend over the years.

\section{Discussion}

The results of this study yielded several interesting findings including the general trend of the book circulation, subjects with higher demands and the lesser demands and the effects of some internal factors on the borrowing rate. The circulation data showed that there is a downward trend in the book circulation over the past 05 years from 2014 to 2018. Several past studies also pointed out the downward trend in the book circulation (Creaser et al., 2006; Kyrillidou, 2006; National Endowment for the Arts [NEA], (2004) 2004; Banks, 2002).

This downward trend in book circulation showed how user information behavior has been changed over the years. Some past studies concluded that library user behavior has shifted from use of printed resources to use of online information resources. Thus, increasing availability of online information resources has a great impact on the reading behavior of the library users. Banks, (2002) stated that database hits has been shifted from 989,784 in 1999 to $1,024,930$ in 2000 . He further noticed that the decline in 
circulation is at a much faster rate than that of the increase in online database usage. Littman and Connaway (2004) carried out a study to compare the usage of 7,880 titles that were available in both print and e-book format at the Duke University Libraries and found e-books received 11 percent more usage than comparable print books. Parallel results were showed in the Open University of Sri Lanka in relation to the online visits by the library users. Accordingly, total user visits of the library website of the Open University of Sri Lanka have been increased from 255,600 in 2016 to 269,000 in 2017 (OUSL Statistical handbook, 2017). This implied that the user information seeking behavior has changed along with the availability of vast online information resources.

The study further explored the effects of library internal factors on the declining book borrowing levels and could identify that there was a significance relationship between the decreased number of book borrowers and the declining rate of book borrowings. Accordingly, it could identify the decreasing rate of book borrowings and the book borrowers are some of the major challenges faced by the libraries in this digital era.

The study further identified the most circulated and least circulated items to derive most demanded and least demanded subjects. This is important in taking effective decisions on some of the library operations such as new acquisitions, preservations, discarding of items. The study could identify literature, technology and social sciences as the subject areas with the highest demand over the 05 years from 2014 to 2018 and religion, history and geography, and arts as the least demand subjects. Highest demand on literature indicates the high motivation of the borrowers for leisure readings because literature covers the poetry, drama, fiction, essays, speeches, etc. in several languages. Further evaluation of the circulation statistics to derive highest demand subcategories of literature, technology and social sciences, identified Sinhala literature and English literature; engineering and management; law and education as the highest demand subcategories. Even though all above subcategories had a highest demand, it showed a declining trend from 2014 to 2018 except the subject of education.

\section{Conclusion}

The analysis indicates that annual book borrowings have been declining for many of the subjects over the past five years. Books in the subject of education was the only subject category which showed an increasing trend from 2014 to 2018. Highest numbers of borrowings were reported in the subcategories of Sinhala literature, English literature, engineering, management, law and education. But, borrowing trend has been declining 
over the years for all these subgroups except education. Number of borrowers has also been declined from 2014 to 2018.

In the digital era, proliferation of information sources and easy access to information sources turn away the readers from the printed materials to the online information sources. However, it is important to carry out a further study to explore factors affecting for the decline in book borrowings and changes happened in accessing information by library users.

It should also emphasize that book borrowing analysis does not produce a complete picture of the library's information resources usage. Library book borrowings do not perfectly measure the usage of library printed resources. Usage pattern of printed information resources inside the library was not taken into consideration in this study, as there are limited opportunities to collect those data. There might be some cases in which some are borrowed and returned without being read. Further, some readers keep books for a long period of time which hinders other's opportunity to use the book. These unavoidable issues are some of the limitations of the study that cannot be controlled.

But, in general the results of the study would be very much useful in developing an active collection in the library. Accordingly, the Library must give priority to the subject areas of Sinhala literature, English literature, engineering, management, law and education in budgetary allocations and acquisition of the books.

\section{References}

Adams, B., \& Noel, B. (2008). Circulation statistics in the evaluation of collection development. Collection Building, 27(2), 71-73. https:// doi.org/10.1108/01604950810870227.

Banks, J. (2002). Weeding book collections in the age of the Internet. Collection Building, 21(3), 113-119. https://doi.org/10.1108/0160 4950210434542.

Carpenter, D., \& Getz, M. (1995). Evaluation of library resources in the field of economics: a case study. Collection management, 20(1-2), 49-89.

Carrigan, D. P. (1996). Data-Guided Collection Development: A Promise Unfulfilled. College \& Research Libraries, 429-437. 
Cheung, S., Chung, T., \& Nesta, F. (2011). Monograph circulation over a 15year period in a liberal arts university. Library Management, 32(6/7), 419-434.

Creaser, C., Maynard, S., \& White, S. (2006). Lisu annual library statisticsFeaturing trend analysis of UK public and academic libraries 19952005. Loughborough : LISU Loughborough University.

Day, M., \& Revill, D. (1995). Towards the active collection: the use of circulation analyses in collection evaluation. Journal of Librarianship and Information Science, 27(3), 149-157. https://doi.org/10.1177/096100069502700304.

Hamaker, C. (1995). Time series circulation data for collection development or: you can't intuit that. Library acquisitions: practice \& theory, 19(2), 191-195. https://doi.org/10.1016/0364-6408(95)00019-6.

Knievel, J. E., Wicht, H., \& Connaway L. S. (2006). Use of Circulation Statistics and Interlibrary Loan Data in Collection Management. College \& Research Libraries, 67(1), 35-49.

Kyrillidou, M., \& Young, M. (2006). A compilation of statistics from the one hundred and twenty-three members of the association of research libraries Compiled and Edited by. Washington. Retrieved from https://files.eric.ed.gov/fulltext/ED501323.pdf.

Littman, J., \& Connaway, L. S. (2004). A circulation analysis of print books and e-books in on academic research library.Library resources and technical services, 48(4), 256-262.

National Endowment for the Arts, NEA (2004), Reading at risk: a survey of literary reading in America, Retrieved from https://files.eric.ed.gov/fulltext/ED484208.pdf

Ochola, J. N. (2002). Use of circulation statistics and interlibrary loan data in collection management. Collection Management, 27(1), 1-13. https://doi.org/10.1300/J105v27n01_01.

The Open University of Sri Lanka.(2018). Statistical Handbook. Sri Lanka Retrieved from http://www.ou.ac.lk/home/images/OUSL/publications /SHB2017\%20PRINT.pdf 